\title{
Revitalisasi Cerita Rakyat Berbasis Teknologi Mixed Reality di Sekolah Dasar
}

\author{
Yunus Abidin ${ }^{1 *}$,Tita Mulyati ${ }^{2}$. Yeni Yuniarti ${ }^{3}$, Tri Falah Nurhuda ${ }^{4}$ \\ 1Universitas Pendidikan Indonesia, Bandung, Indonesia \\ 2Universitas Pendidikan Indonesia, Bandung, Indonesia \\ 3Universitas Pendidikan Indonesia, Bandung, Indonesia \\ ${ }^{4}$ Universitas Pendidikan Indonesia, Bandung, Indonesia \\ *Corresponding author: yunusabidin@upi.edu
}

\begin{abstract}
Folklore is seen as one of the outdated and ancient types of literature. This has an impact on the low interest of students to learn folklore. Whereas on the other hand folklore is a literary work that is full of cultural values and is very important for students to learn at school. Based on this fact, this research focuses on efforts to package folklore using mixed reality technology. Efforts to package folklore using this technology are carried out through Educational Design Research (EDR). This study involved the respondents of the assessment team, namely material experts and learning media experts. Data were collected using a questionnaire. The data was processed by descriptive statistics. Based on the results of the study, it can be stated that the product developed in this study is categorized as very good. Materially, folklore packaged with mixed reality technology in terms of the feasibility of content, presentation components, linguistic components, and contextuality are categorized as very good. Judging from the technical quality aspect of the mixed reality design, the quality of the marker books, and the quality of the media are generally considered to be in the very good category. Based on the results of this study, folklore packaged with mixed reality technology is suitable for use in learning folklore in elementary schools.
\end{abstract}

keywords: folklore; instructional media; mixed reality

\section{ABSTRAK}

Cerita rakyat dipandang sebagai salah jenis sastra yang tertinggal zaman dan masih kuno. Hal ini berimbas pada rendahnya minat siswa untuk mempelajari cerita rakyat. Padahal di sisi lain cerita rakyat adalah karya sastra yang sarat dengan nilai budaya dan sangat penting untuk dipelajari siswa di sekolah. Berdasarkan kenyataan tersebut, penelitian ini memfokuskan diri pada upaya mengemas cerita rakyat dengan menggunakan teknologi mixed reality. Upaya pengemasan cerita rakyat dengan menggunakan teknologi tersebut dilakukan melalui penelitian desain pendidikan (EDR). Penelitian ini melibatkan responden tim penilai karya yakni ahli materi dan ahli media pembelajaran. Kuesioner digunakan untuk mengumpulkan data. Data diolah secara statistika deskriptif. Berdasarkan hasil penelitian dapat dikemukakan bahwa produk yang dikembangkan dalam penelitian ini berkategori sangat baik. Secara materi, cerita rakyat yang dikemas dengan teknologi mixed reality ditinjau dari aspek kelayakan komponen isi, penyajian, kebahasaan, dan kontekstulitasnya berkategori sangat baik. Ditinjau dari aspek kualitas teknis desain mixed reality, kualitas buku marker, dan kualitas media secara umum dinilai berkategori sangat baik. Berdasarkan hasil penelitian ini cerita rakyat yang dikemas dengan teknologi mixed reality layak digunakan dalam pembelajaran cerita rakyat di sekolah dasar.

kata kunci: cerita rakyat; media pembelajaran; mixed reality

\section{Pendahuluan}

Perkembangan abad ke-21 ini telah membawa dampak terhadap perkembangan dalam berbagai aspek seperti teknologi dan informasi, ilmu pengetahuan yang ujungnya berimbas pada bidang pendidikan (Jan, 2017). Sehubungan dengan hal tersebut, pendidikan di abad ke21 dihadapkan dengan sejumlah tantangan besar yakni membangun para siswa yang literat teknologi dan berpandangan ke masa depan serta literat budaya (Teo, 2019). Berdasarkan hal 
tersebut, perlu adanya sebuah perubahan terhadap pola pembelajaran dalam pendidikan Indonesia untuk lebih mengembangkan pengetahuan, pemahaman, dan keterampilan yang tinggi sejalan dengan kemajuan teknologi abad 21 serta tidak abai terhadap pengetahuan inti budaya (Boholano, 2017) .

Guna mewujudkan tujuan pendidikan tersebut, salah satu hal yang harus dilakukan adalah meningkatkan literasi membaca siswa dan literasi budaya siswa. Padahal di sisi lain pendidikan di Indonesia dihadapkan pada kenyataan rendahnya kemampuan literasi membaca siswanya. Berdasarkan hasil tes dan survei PISA tahun 2018 diperoleh data bahwa performa siswa Indonesia masih tergolong rendah. Rata-rata skor pencapaian siswa Indonesia untuk literasi membaca berada di peringkat 70. Peringkat dan rata-rata skor Indonesia tersebut jauh berbeda dengan hasil tes dan survei PISA pada tahun 2015 yang berada diperingkat 62 (OECD, 2016) (OECD, 2019). Dengan demikian, bahwa tingkat literasi siswa di Indonesia mengalami penurunan dari tahun 2015 sampai dengan tahun 2018.

Ditinjau dari aspek literasi budaya, siswa Indonesia pun memiliki masalah yang sejenis, yakni rendahnya literasi budaya siswa. Literasi budaya berawal dari konsep kosmopolitanisme yaitu sebagai perwujudan identitas seseorang (etnis, nasional, budaya) dan modal budaya yang terakumulasi melalui pengalaman dengan proses pendidikan (Johnson, 2014). Sejalan dengan definisi ini, rendahnya literasi budaya siswa ditunjukkan dengan semakin melemahnya rasa kebanggaan siswa terhadap identitas etnis yang dimilikinya, serta melemahnya rasa cinta tanah air dan budaya yang dimilikinya. Dapat dipahami bahwa dengan memiliki keterampilan literasi budaya, seseorang dapat meningkatkan interaksi sosialnya dan dapat juga meningkatkan pengetahuan terhadap norma yang berlaku di sekitarnya.

Sejalan dengan permasalahan di atas, salah satu cara untuk mengurai permasalahan ini adalah membina literasi membaca sekaligus membina literasi budaya siswa. Upaya pembinaan ini dapat dilakukan dengan cara mendekatkan kembali siswa terhadap cerita rakyat yang mengandung nilai-nilai budaya. Dipilihnya cerita rakyat sebagai salah satu solusi untuk mengembangkan dua literasi siswa tersebut sejalan dengan kenyataan bahwa cerita rakyat memiliki vitalitas yang melekat pada penduduk asli dan kekuatan bahasa daerahnya (Farr, 2009). Pada saat yang sama, cerita rakyat mengungkapkan kehidupan dan semangat orang-orang biasa dan menggambarkan emosi dan cara berpikir mereka. Praktis semua siswa mengenal cerita rakyat meskipun mereka mungkin tidak menyadari karakternya yang khas.

Lebih jauh, cerita rakyat terdiri dari kumpulan besar literatur yang terbukti menarik bagi pembaca (Palmer \& Davis, 1990). Kebanyakan cerita rakyat disajikan dengan gaya langsung dan sederhana yang menggabungkan aksi dan karakter warna-warni yang menarik bagi semua tingkatan pembaca. Dalam konteks pembelajaran, pembelajaran berbasis cerita rakyat (folklore) adalah istilah yang digunakan untuk mewakili penggunaan dongeng untuk mempelajari topik yang kompleks (Humpherys \& Babb, 2020). Selain itu, pembelajaran cerita rakyat (folklore) dapat meningkatkan kemampuan ingatan siswa atau kemampuan kognitif siswa (Agbenyega dkk., 2017).

Menyadari pentingnya cerita rakyat tersebut, perlu ada solusi yang dipilih agar cerita rakyat bisa memikat dan meningkatkan motivasi siswa membacanya. Solusi tersebut pada dasarnya harus mampu menampilkan cerita rakyat dalam wujud baru yang menarik. Cerita rakyat harus dikemas dengan baik dan bernuansa kekinian sehingga dapat menarik siswa 
untuk membaca dan mengkajinya kembali. Pengemasan cerita rakyat yang memenuhi kriteria tersebut adalah dengan mengoptimalkan penggunaan teknologi mixed reality.

Mixed Reality (MR) adalah teknologi dunia virtual yang mencampuran konsep antara Augmented Reality dengan Virtual Reality. Virtual Reality (VR) dan Augmented Reality (AR) merupakan jenis teknologi yang berbeda cara penggunaanya. AR adalah teknologi yang menyajikan perluasan dunia fisik dengan menggunakan lapisan informasi digital ke dalamnya seperti benda-benda yang tidak ada di dunia nyata menjadikanya seolah-olah ada dilingkungan nyata. VR merupakan teknologi yang mampu menempatkan seolah-olah seseorang seperti berada di lingkungan visual yang terlihat pada kacamata VR (Huang dkk., 2019).

Berkenaan dengan MR, beberapa penelitian telah membuktikan bahwa penggunaan MR dapat meningkatkan hasil belajar siswa. Bukan hanya sekadar meningkatkan kemampuan pada siswa tertentu, penggunaan MR telah pula diklaim mampu mengembangkan kemampuan belajar pada siswa dengan kemampuan spasial yang rendah (Weng dkk., 2018). Penelitian lain juga membuktikan bahwa penerapan MR dapat memberikan kontribusi yang sangat signifikan terhadap potensi kolaborasi dengan teman sebayanya (Beyoglu dkk., 2020). Dengan demikian, bahwa penerapan MR dalam proses pembelajaran dapat menunjang terhadap perkembangan kemampuan siswa serta dapat meningkatkan komunikasi dan kolaborasi antar siswa yang sejalan dengan kompetensi di abad 21.

Dasar pemikiran lain yang mendukung pengemasan kembali cerita rakyat melalui teknologi MR adalah bahwa produk MR dapat dikembangkan dengan menggunakan kacamata virtual yang terintegrasi dengan cloud atau server baik online maupun offline sehingga dapat menampilkan gambaran nyata dalam bentuk virtual sehingga dapat memberikan kesan pembelajaran kepada siswa lebih menarik dan menyenangkan (SiNoplu \& Karaoğlan Yilmaz, 2021). Dengan demikian, teknologi yang telah dirancang bertujuan untuk meningkatkan kemampuan literasi teknologi, literasi membaca, sekaligus literasi budaya para siswa. Melalui pembelajaran cerita rakyat berbasis MR siswa dapat berinteraksi dengan karakter ataupun artefak budaya dari cerita rakyat dalam bentuk virtual. Selain itu juga, teknologi tersebut dapat memberikan informasi yang berkesinambungan dan berkorelasi dengan pembelajaran di sekolah.

Sejalan dengan uraian di atas, tujuan dari penelitian ini adalah untuk merancang bangun media pembelajaran cerita rakyat berbasis MR yang layak digunakan dalam pembelajaran. Tujuan jangka panjang pada penelitian ini adalah teknologi ini mampu digunakan oleh guru dan siswa sekolah di masa yang akan datang serta dapat dikembangkan menjadi teknologi yang multiguna dalam penunjang pembelajaran.

\section{Metode Penelitian}

Metode penelitian yang digunakan dalam penelitian ini yaitu model penelitian desain pendidikan dan atau Educational Design Research (EDR). Penelitian desain/pengembangan sebagai strategi yang layak untuk penelitian yang bertanggung jawab secara sosial dalam teknologi pendidikan. Salah satu keuntungan utama dari penelitian desain adalah membutuhkan praktisi dan peneliti untuk berkolaborasi dalam mengidentifikasi masalah pengajaran dan pembelajaran yang nyata, pembuatan solusi prototipe berdasarkan prinsipprinsip desain yang ada, dan pengujian dan penyempurnaan solusi prototipe dan prinsip- 
prinsip desain sampai hasil yang memuaskan telah dicapai oleh semua pihak(Akker, 2006). Penelitian desain bukanlah kegiatan yang dapat dilakukan oleh peneliti individu secara terpisah dari praktik; sifatnya memastikan bahwa kemajuan akan dibuat sehubungan dengan, setidaknya, klarifikasi masalah yang dihadapi guru dan peserta didik, dan idealnya, penciptaan dan adopsi solusi seiring dengan penjelasan model dan prinsip desain yang kuat.

Salah satu model yang dapat digunakan untuk mendesain dan mengembangkan produk adalah model ADDIE. Model ADDIE meliputi analisis, desain, pengembangan, implementasi, dan evaluasi (Richey \& Klein, 2005). Model pengembangan ADDIE adalah model desain pembelajaran yang sistematis. Terdapat tahapan yang harus dilakukan untuk mengembangkan suatu produk pengembangan yang memungkinkan peneliti untuk melakukan evaluasi pengembangan pada setiap tahapnya.

Sejalan dengan uraian di atas, data penelitian ini dikumpulkan menggunakan instrumen berupa kuesioner. Sumber data penelitian ini adalah 5 orang ahli materi dan 5 orang ahli media yang berfungsi untuk menimbang media MR yang dikembangkan. Fokus penilaian pada aspek bahasa meliputi aspek kelayakan isi, komponen penyajian, komponen kebahasaan, dan kontekstulitasnya. Fokus aspek media mencakup teknis desain $M R$, kualitas buku marker, dan kualitas media secara umum. Data yang terkumpul diolah dengan menggunakan teknik analisis statistika deskriptif.

\section{Hasil dan Pembahasan}

Sejalan dengan metode dan teknis pengembangan media yang digunakan dalam penelitian ini dapat dikemukakan bahwa pengembangan media pembelajaran cerita rakyat melalui pengemasan cerita rakyat dengan teknologi MR dilakukan melalui berapa tahapan pengembangan. Tahap pertama pengembangan adalah menyusun garis besar program media (GBPM). Pembuatan GBPM berfungsi untuk meminimalisasi kemungkinan kesalahan materi dalam pengembangan media pembelajaran. Langkah-langkah yang dapat dilakukan dalam menyusun GBPM meliputi: (1) mengidentifikasi kebutuhan dan karakteristik siswa, (2) merinci tujuan pembelajaran yang hendak dicapai, (3) merumuskan butir-butir materi atau pokok bahasan, dan (4) merumuskan bentuk sajian materi pembelajaran. Tahap kedua adalah pengembangan flowchart. Flowchart atau diagram alur yang digunakan yaitu flowchart program yang menerangkan dengan rinci bagaimana langkah-langkah atau urutan prosedur dari suatu program dijalankan.

Tahap selanjutnya adalah pembuatan storyboard. Stroryboard dimaksudkan agar flowchart yang telah dibuat dapat diuraikan dengan lebih rinci di setiap frame/slide. Storyboard atau susun alur cerita merupakan gambaran detail konten dari aplikasi yang akan dibuat. Pengembangan beberapa storyboard dalam penelitian ini mengacu pada beberapa konsep dasar sebagai berikut. 


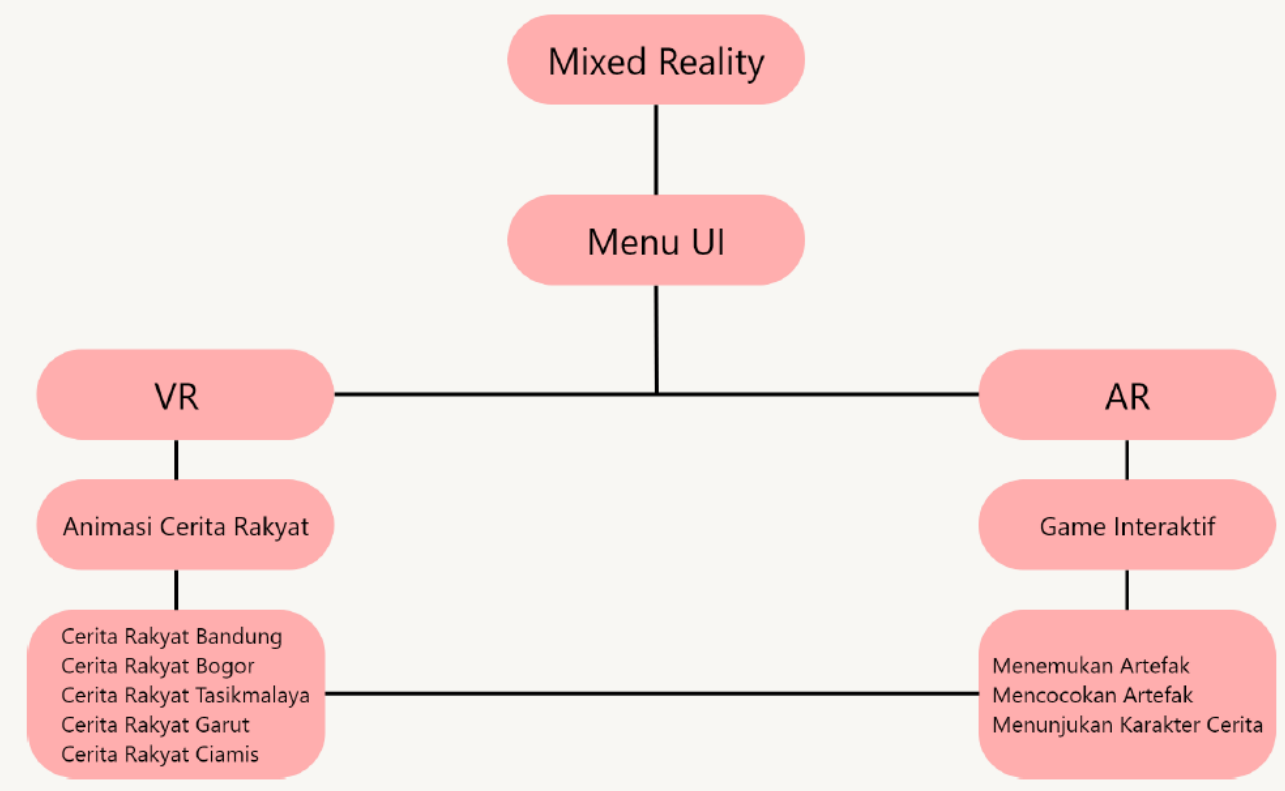

\section{VR Sebagai Pemaparan Dongeng}

Gambar 1. Aplikasi Umum MR Folklor

1) Dalam media virtual reality isi content di dalamnya berupa animasi cerita rakyat(dongeng).

2) Di dalam virtual reality ini juga terdapat virtual button untuk memilih cerita rakyat sesuai dengan daerah seperti cerita rakyat Bandung, cerita rakyat Tasikmalaya,dsb.

3) Perspektif content dalam virtual reality ini dapat berbentuk perspektif augmented reality; content virtual reality dapat tampil seperti augmented reality

4) Media penghubung yang digunakan menggunakan cardboard yang dapat meningkatkan rasa realistis dan kepuasan oleh peserta didik.

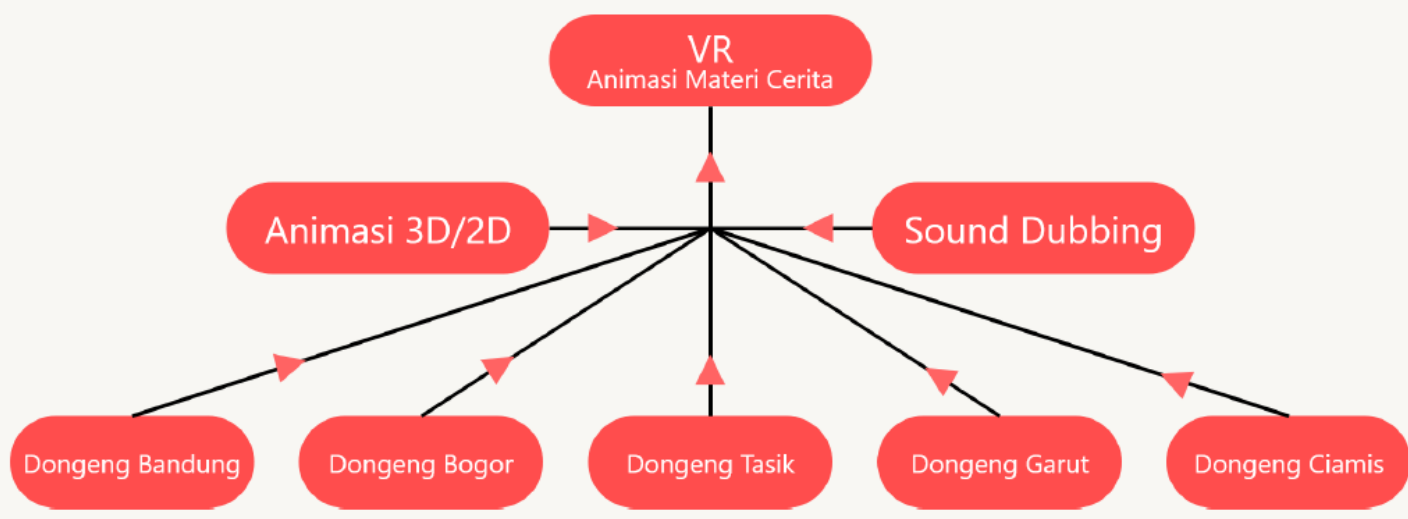

Gambar 2. Aplikasi VR Folklor 


\section{AR Sebagai Game Interaktif}

1) Di dalam augmented reality sebagai game interakrif isi content yang terdapat di dalamnya berupa penampilan artefak-artefak yang terdapat di masing-masing cerita rakyat yang ditampilkan dalam virtual reality.

2) Di dalam augmented reality juga terdapat menu UI dalam bentuk virtual button yang dapat disentuh oleh siswa/peserta didik.

3) Marker yang digunakan dalam menampilkan augmented reality ini adalah menggunakan marker sederhana yaitu menggunakan image target sebanyak 5 buah dalam satu meja.

4) Jenis game interaktif yang terdapat dalam aplikasi ini adalah:
a) Menemukan artefak dongeng
b) Mencocokkan artefak dongeng
c) Menunjukkan tokoh/karakter dongeng

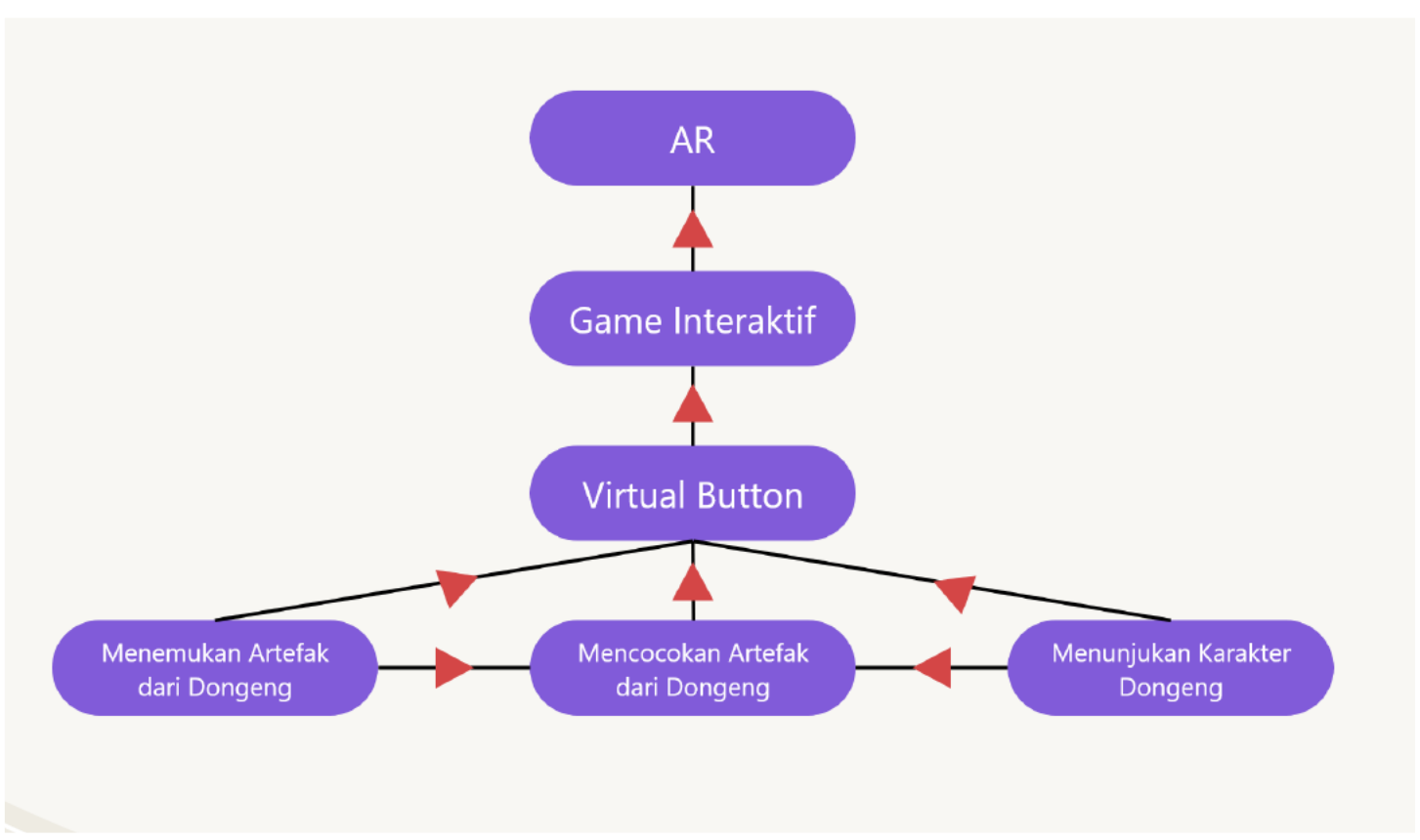

Gambar 3. Aplikasi AR Folklor

Berdasarkan pedoman di atas, salah satu langkah pengembangan pada aplikasi VR adalah mengembangkan video VR. Pengembangan video VR diawali dengan menyusun scene/ tahapan cerita secara mendetail sehingga ada kesesuaian antara video yang dihasilkan dengan tahapan cerita dan rancangan VR yang harus dikembangkan. Salah satu scene cerita pada video VR yang dikembangkan dapat disajikan sebagai berikut. 


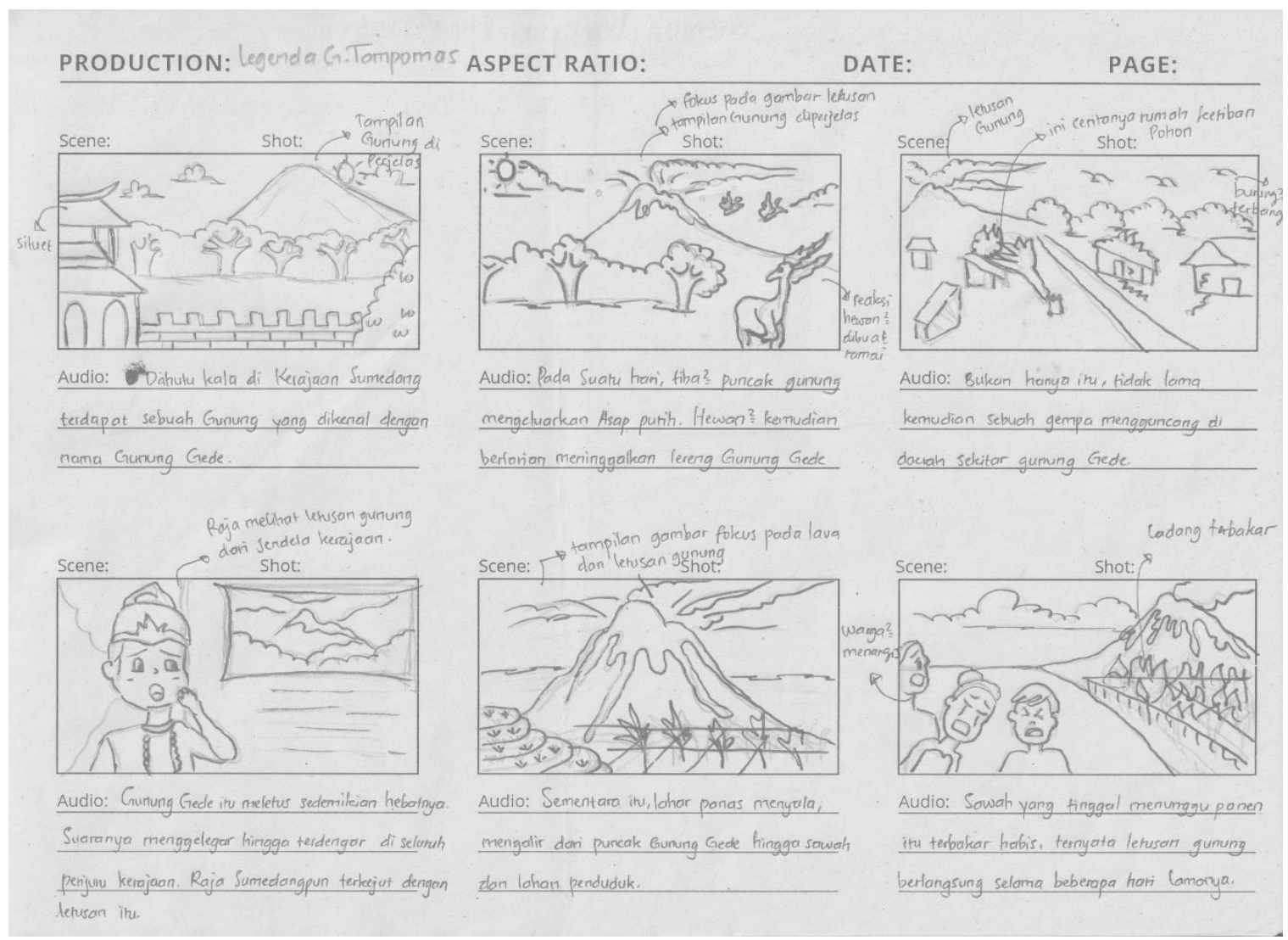

Gambar 4. Salah Satu Scene pada Aplikasi AR Folklor

Media yang telah dikembangkan selanjutnya diuji validasi oleh para pakar untuk menentukan kesesuaian dan kelayakannya untuk digunakan pembelajaran. Berdasarkan hal tersebut berikut disajikan hasil uji kelayakgunaan media yang dikembangkan berdasarkan para ahli bahasa dan ahli media.

Validasi dari ahli materi dilakukan oleh lima orang dosen yang ahli dalam bidang pembelajaran Bahasa dan Sastra Indonesia. Validasi kepada ahli materi bertujuan untuk mendapatkan tanggapan berupa penilaian dan juga saran mengenai beberapa aspek yang ada pada produk yang dikembangkan. Berikut merupakan hasil penilaian atau validasi dari ahli materi.

Tabel 1. Penilaian Ahli Materi

\begin{tabular}{llllll}
\hline No. & Aspek & Butir & Skor Total & $\begin{array}{l}\text { Skor } \\
\text { Diperoleh }\end{array}$ & Persentase (\%) \\
\hline 1. & Kelayakan Isi/Materi & 7 & 175 & 160 & 91,4 \\
2. & Komponen Penyajian & 4 & 100 & 85 & 85 \\
3. & Komponen Kebahasaan & 3 & 75 & 65 & 86,67 \\
4. $\quad$ Kontekstual & 3 & 75 & 60 & 80 \\
Rata-rata & & & & 85,76 \\
\hline
\end{tabular}


Kelayakan isi/materi menurut pandangan ahli materi memperoleh skor persentase sebesar $91.4 \%$ yang diinterpretasikan bahwa produk yang dikembangkan termasuk "Sangat Baik" dari segi isi/materi. Penilaian tersebut berdasarkan indikator-indikator yang meliputi: (1) kesesuaian isi dengan KD, (2) kesesuaian isi dengan silabus, (3) kesesuaian isi dengan indikator, (4) kedalaman materi, (4) kebenaran konsep keilmuan, (5) ketepatan visualisasi materi, (6) kesesuaian dengan perkembangan ilmu.

Komponen penyajian dari indikator yang meliputi: (1) kelogisan penyajian, (2) keruntutan penyajian, (3) koherensi, dan (4) kesesuaian dan ketepatan objek 3D yang muncul, mendapatkan skor persentase sebesar 85\% yang diinterpretasikan bahwa produk yang dikembangkan termasuk "Sangat Baik" dari segi komponen penyajian aplikasi dan buku marker.

Media pembelajaran ini memiliki sedikit komponen kebahasaan. Berdasarkan sudut pandang ahli, komponen kebahasaan media MR folklor memperoleh skor persentase sebesar 86,67\% yang diinterpretasikan bahwa produk yang dikembangkan termasuk "Sangat Baik". Indikator kebahasaan meliputi: (1) penggunaan dan penyajian bahasa sesuai dengan tingkat perkembangan siswa, (2) ketepatan tata bahasa dan ejaan yang digunakan, dan (3) ketepatan dalam penggunaan simbol yang mewakili kata dapat mudah dipahami.

Media ini dapat dinilai kontekstual melalui indikator yang meliputi: (1) keterikatan materi yang disajikan dengan kehidupan dunia nyata, (2) kemampuan mendorong siswa menghubungkan skemata dengan aplikasinya dalam kehidupan sehari-hari, dan (3) pemodelan (modelling). Berdasarkan pandangan ahli terkait komponen konstektual media, skor persentase yang diperoleh sebesar $80 \%$ yang diinterpretasikan bahwa produk yang dikembangkan termasuk "Baik" dari segi kontekstual.

Berdasarkan penilaian dari sudut pandang ahli materi di atas, dapat disimpulkan bahwa media pembelajaran ini sudah laik guna tanpa revisi. Persentase rata-rata yang diperoleh sebesar 85,76\%, yang diinterpretasikan bahwa media pembelajaran secara keseluruhan tergolong kategori "Sangat Baik" menurut penilaian maupun ulasan dari ahli materi.

Validasi dari ahli media dilakukan oleh lima orang ahli Multimedia. Validasi kepada ahli media bertujuan untuk mendapatkan tanggapan berupa penilaian dan juga saran mengenai produk yang dikembangkan, yakni media pembelajaran berbasis MR Folklor yang dilengkapi dengan buku market. Berikut merupakan hasil penilaian atau validasi dari ahli media.

Tabel 2. Penilaian Ahli Media

\begin{tabular}{|c|c|c|c|c|c|}
\hline No. & Aspek & Butir & Skor Total & $\begin{array}{l}\text { Skor } \\
\text { Diperoleh }\end{array}$ & $\begin{array}{l}\text { Persentase } \\
(\%)\end{array}$ \\
\hline 1. & $\begin{array}{l}\text { Kualitas Teknis } \\
\text { Aplikasi MR }\end{array}$ & & 200 & 185 & 92,5 \\
\hline 2. & Buku Marker & 9 & 225 & 200 & 88,8 \\
\hline 3. & Kualitas Media & 2 & 50 & 50 & 100 \\
\hline \multicolumn{5}{|c|}{ Rata-rata } & 93,76 \\
\hline
\end{tabular}

Kualitas teknis dan desain aplikasi teknologi MR memperoleh persentase penilaian sebesar 92,5\% yang menandakan bahwa kualitas media termasuk kategori "Sangat Baik" dengan indikator yang meliputi: (1) penampilan unsur tata letak tombol-tombol navigasi pada aplikasi memudahkan pengguna, (2) kejelasan pelafalan audio pada aplikasi, (3) kemenarikan 
desain tampilan aplikasi sesuai dengan karakteristik siswa, (4) penggunaan komposisi warna harmonis dan enak dilihat, (5) objek 3D yang muncul, (6) aplikasi membantu dalam mengenalkan isi cerita, (7) menarik perhatian, dan (8) mudah diakses.

Penilaian media berupa buku marker memiliki indikator yang meliputi: (1) kesesuaian ukuran buku dengan cara membawanya, (2) kesesuaian ukuran buku dengan isi, (3) desain sampul/cover buku menarik, (4) kualitas kertas buku tidak mudah rusak, (5) kerapian tata letak teks dan gambar yang ada pada buku, (6) warna yang digunakan sesuai dengan karakteristik peserta didik, (7) gambar dan teks yang digunakan menarik, (8) menggambarkan materi ajar, dan (9) marker mudah dibaca. Persentase yang diperoleh sebesar 88,8\% dan dapat diinterpretasikan bahwa buku termasuk kategori "Sangat Baik".

Kualitas media meliputi aplikasi dengan fitur AR dan buku yang sudah dicetak. Indikator penilaian kualitas media meliputi: (1) kegunaan media, dan (2) kegunaan media dalam memfasilitasi siswa untuk aktif dalam pembelajaran. Kualitas media memperoleh skor persentase sebesar 100\%, yang berarti kualitas media "Sangat Baik".

Selain menilai ada beberapa catatan yang dikemukakan oleh ahli media. Saran yang diberikan yaitu berkenaan perlunya uji coba aplikasi pada berbagai kamera smartphone agar pengguna mengetahui tingkat kompatibilitas aplikasi yang dibuat. Hal ini disebabkan aplikasi ini yang dipasang pada smartphone yang memiliki spesifikasi rendah tidak dapat berjalan dengan baik. Di sisi lain, secara keseluruhan berdasarkan penilaian dari sudut pandang ahli media di atas, dapat disimpulkan bahwa media pembelajaran ini sudah laik guna dengan catatan. Persentase rata-rata yang diperoleh sebesar 85,75\% dan 93,76\%, yang diinterpretasikan bahwa media pembelajaran secara keseluruhan tergolong "Sangat Baik" menurut penilaian maupun ulasan dari ahli media.

Keberhasilan pengembangan MR Folklor dalam penelitian ini diharapkan mampu meningkatkan kemampuan belajar siswa. Lebih jauh, MR folklor yang dikembangkan akan mampu pula mengembangkan literasi budaya siswa. Hal ini sangat beralasan sejalan dengan penelitian yang pernah dilakukan yang membuktikan bahwa penggunaan teknologi AR sangat efektif digunakan dalam proses pembelajaran (Mustaqim, 2016). Dalam bidang matematika telah pula digunakan teknologi khususnya teknologi VR yang telah terbukti pula mampu meningkatkan hasil belajar siswa (Rachman, 2017). Bidang lain yang menggunakan teknologi AR untuk pembelajaran di sekolah dasar adalah pembelajaran pengenalan bahasa Jawa yang telah pula membuktikan pada pemanfaatan teknologi efektif digunakan(Kusuma dkk., 2019).

Folklor yang dikembangkan dalam penelitian memadukan penggunaan VR sebagai media untuk mengemas cerita. Dengan pengemasan ini siswa diharapkan mampu menyaksikan cerita dengan penuh konsentrasi sehingga pemahamannya terhadap cerita menjadi lebih baik. Teknologi AR digunakan untuk memberikan pengalaman lebih tentang tokoh, seting, dan berbagai komponen lain yang berhubungan dengan folklor. Melalui dua pemaduan teknologi ini diyakini siswa mampu lebih tertarik terhadap folklor dan lebih memahami nilai-nilai yang terkandung di dalamnya. Hal ini diperkuat oleh salah satu penelitian yang berbasis MR di Indonesia dalam bidang agama yang membuktikan bahwa dengan memadukan VR dan MR siswa semakin paham tentang tata cara salat dan mampu melaksanakan salat dengan tepat (Yusuf dkk., 2021). 


\section{Kesimpulan}

Berdasarkan hasil penelitian yang telah dilaksanakan dapat diambil beberapa kesimpulan. Kesimpulan pertama adalah bahwa penelitian ini membuktikan upaya merevitalisasi cerita rakyat melalui upaya pengemasan cerita rakyat dengan menggunakan teknologi MR dapat dilakukan dengan beberapa tahapan pengembangan yang detail dan sistematis. Upaya pengemasan yang detail dan sistematis ini dapat menghasilkan MR folklor sebagai produk yang dihasilkan penelitian ini. Produk MR folklor yang dihasilkan mendapatkan penilaian yang sangat baik, baik berdasarkan hasil validasi dan penilaian ahli materi dan validasi dan penilaian ahli media. Tahap selanjutnya media yang berhasil dikembangkan perlu pula pengujian kelayakan baik dari sisi siswa sebagai calon pemakai maupun sisi guru sebagai calon pengguna. Penilaian kelayakan lanjutan dari kedua sisi ini diharapkan media MR folklor yang dikembangkan dapat diaplikasikan dalam pembelajaran di sekolah dasar baik untuk meningkatkan literasi membaca maupun untuk meningkatkan literasi budaya dan literasi teknologi lebih jauhnya.

\section{Daftar Pustaka}

Agbenyega, J., Tamakloe, D., \& Klibthong, S. (2017). Folklore epistemology: How does traditional folklore contribute to children's thinking and concept development? International Journal of Early Years Education, 25(2), 112-126. https://doi.org/10.1080/09669760.2017.1287062

Akker, J. J. H. van den (Ed.). (2006). Educational design research. Routledge.

Beyoglu, D., Hursen, C., \& Nasiboglu, A. (2020). Use of mixed reality applications in teaching of science. Education and Information Technologies, 25(2020), 2471-4285. https://doi.org/10.1007/s10639-020-10166-8

Boholano, H. (2017). Smart social networking: 21st Century teaching and learning skills. Research in Pedagogy, 7(2), 21-29. https:/ / doi.org/10.17810/2015.45

Farr, T. (2009). Some uses of folklore in teaching English. Peabody Journal of Education, 17(4), 260-262. https:/ / doi.org/10.1080/01619564009535581

Huang, K.-T., Ball, C., Francis, J., Ratan, R., Boumis, J., \& Fordham, J. (2019). Augmented Versus Virtual Reality in Education: An Exploratory Study Examining Science Knowledge Retention When Using Augmented Reality/Virtual Reality Mobile Applications. Cyberpsychology, Behavior, and Social Networking, 22(2), 105-110. https://doi.org/10.1089/cyber.2018.0150

Humpherys, S. L., \& Babb, J. (2020). Using Folklore, Fables, and Storytelling as a Pedagogical Tool in Assessment Exams. 20.

Jan, H. (2017). Teacher of 21st Century: Characteristics and Development. 5.

Johnson, P. (2014). Cultural literacy, cosmopolitanism and tourism research. Annals of Tourism Research, 44(Januari 2014), 255-269. https:// doi.org/10.1016/j.annals.2013.10.006

Kusuma, F. E. E., Setyawan, M. B., \& Zulkarnain, I. A. (2019). PENERAPAN TEKNOLOGI AUGMENTED REALITY BERBASIS ANDROID SEBAGAI MEDIA PEMBELAJARAN PENGENALAN AKSARA JAWA DI SDN 1 SIDOREJO PONOROGO. KOMPUTEK, 3(1), 61. https://doi.org/10.24269/jkt.v3i1.203

Mustaqim, I. (2016). PEMANFAATAN AUGMENTED REALITY SEBAGAI MEDIA PEMBELAJARAN. Jurnal Pendidikan Teknologi dan Kejuruan, 10.

OECD. (2016). PISA 2015 Results (Volume I): Excellence and Equity in Education. OECD. https:// doi.org/10.1787/9789264266490-en

OECD. (2019). PISA 2018 Results (Volume I): What Students Know and Can Do. OECD. https:// doi.org/10.1787/5f07c754-en 
Palmer, J., \& Davis, J. (1990). Using Games and Folklore to Extend Children's Literature. The Clearing House: A Journal of Educational Strategies, Issues and Ideas, 63(9), 395-401. https://doi.org/10.1080/00098655.1990.10114138

Rachman, A. (2017). PEMANFAATAN TEKNOLOGI 3D VIRTUAL REALITY PADA PEMBELAJARAN MATEMATIKA TINGKAT SEKOLAH DASAR. 3, 8.

Richey, R. C., \& Klein, J. D. (2005). Developmental research methods: Creating knowledge from instructional design and development practice. Journal of Computing in Higher Education, 16(2), 23-38. https:// doi.org/10.1007/BF02961473

SiNoplu, M., \& Karaoğlan Yilmaz, F. G. (2021). Review of Articles Related to Mixed Reality in Education. Journal of Teacher Education and Lifelong Learning. https:// doi.org/10.51535/tell.894508

Teo, P. (2019). Teaching for the 21st century: A case for dialogic pedagogy. Learning, Culture and Social Interaction, 21, 170-178. https:/ /doi.org/10.1016/j.lcsi.2019.03.009

Weng, C., Abirami, R., Weng, A., \& Zagita, C. (2018). Mixed Reality in Science Education as a Learning Support: A Revitalized Science Book. Journal of Educational Computing Research, 57(3), 777-807. https://doi.org/10.1177/0735633118757017

Yusuf, M., Fauziah, F., \& Gunaryati, A. (2021). TEKNOLOGI MIXED REALITY PADA APLIKASI TUNTUNAN SHALAT MAGHRIB MENGGUNAKAN ALGORITMA FAST CORNER DETECTION DAN LUCAS KANADE. JIPI (Jurnal Ilmiah Penelitian dan Pembelajaran Informatika), 6(1), 82-93. https:/ / doi.org/10.29100/jipi.v6i1.1905 